\title{
Laser filament-induced aerosol formation
}

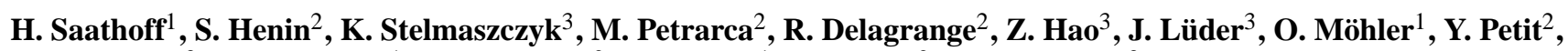 \\ P. Rohwetter ${ }^{3}$, M. Schnaiter ${ }^{1}$, J. Kasparian ${ }^{2}$, T. Leisner ${ }^{1}$, J.-P. Wolf ${ }^{2}$, and L. Wöste ${ }^{3}$ \\ ${ }^{1}$ Karlsruhe Institute of Technology, Institute for Meteorology and Climate Research, Hermann-von-Helmholtz-Platz 1, \\ 76344 Eggenstein-Leopoldshafen, Germany \\ ${ }^{2}$ GAP, Université de Genève, Chemin de Pinchat 22, 1211 Genève 4, Switzerland \\ ${ }^{3}$ Institut für Experimentalphysik, Freie Universität Berlin, Arnimallee 14, 14195 Berlin, Germany \\ Correspondence to: J. Kasparian (jerome.kasparian@ unige.ch)
}

Received: 18 October 2012 - Published in Atmos. Chem. Phys. Discuss.: 20 November 2012

Revised: 27 March 2013 - Accepted: 9 April 2013 - Published: 3 May 2013

\begin{abstract}
Using the aerosol and cloud simulation chamber AIDA, we investigated the laser filament induced particle formation in ambient air, humid synthetic air, humid nitrogen, argon-oxygen mixture, and pure argon in order to simulate the particle formation under realistic atmospheric conditions as well as to investigate the influence of typical gasphase atmospheric constituents on the particle formation. Terawatt laser plasma filaments generated new particles in the size range 3 to $130 \mathrm{~nm}$ with particle production rates ranging from $1 \times 10^{7}$ to $5 \times 10^{9} \mathrm{~cm}^{-3}$ plasma s$^{-1}$ for the given experimental conditions. In all cases the particle formation rates increased exponentially with the water content of the gas mixture. Furthermore, the presence of a few ppb of trace gases like $\mathrm{SO}_{2}$ and $\alpha$-pinene clearly enhanced the particle yield by number, the latter also by mass. Our findings suggest that new particle formation is efficiently supported by oxidized species like acids generated by the photoionization of both major and minor components of the air, including $\mathrm{N}_{2}, \mathrm{NH}_{3}, \mathrm{SO}_{2}$ and organics.
\end{abstract}

\section{Introduction}

In recent years femtosecond laser pulses fired into the atmosphere have shown to generate self-guided filaments (Kasparian et al., 2003; Couairon and Mysyrowicz, 2007; Bergé et al., 2007; Kasparian and Wolf, 2008; Chin et al., 2005) in a dynamic balance between Kerr self-focusing and defocusing by the self-generated plasma and/or negative higher order Kerr terms (Béjot et al., 2010). They can deliver an intensity as high as $5 \times 10^{13} \mathrm{~W} \mathrm{~cm}^{-2}$ at kilometer-range distances (Rodriguez et al., 2004), sufficient for ionizing and photoox- idizing the air (Petit et al., 2010), allowing a very rich plasma chemistry implying both neutral and ionized species (Kossyi et al., 1992; Xu et al., 2009; Dotan et al., 1997; Bardsley, 1968; Braginskiy et al., 2005).

Filaments generated by ultrashort laser pulses were recently proposed as candidates to promote condensation of water in the atmosphere (Rohwetter et al., 2010) or generate snow (Ju et al., 2012). However, so far only little information on the laser-induced particle formation, potential growth of these particles, and the corresponding uptake of water on these particles is available (Rohwetter et al., 2011). It was shown, in particular, that uptake of water on laserinduced particles is assisted by laser-generated hygroscopic $\mathrm{HNO}_{3}$ (Petit et al., 2010; Rohwetter et al., 2011), generated in the plasma trail left behind by the laser filaments. Similar results have also been reported for illumination with ultraviolet light (Yoshihara, 2005; Sorokin and Arnold, 2009; Sorokin, 2010). No data have been however available to date on the laser filament capability of nucleating new particles from the gas phase.

Therefore, this work aims at systematically studying the laser filament-induced particle formation in humid inert gases, in humid air, and in ambient air under well-controlled conditions with extremely low background particle concentration. The experiments were performed in the large-scale aerosol and cloud chamber AIDA (Aerosol Interaction and Dynamics in the Atmosphere) (Möhler et al., 2003; Schnaiter et al., 2012) under illumination by the TW-class mobile laser system Teramobile (Wille et al., 2002). Temperature, relative humidity, trace gas levels, and laser power were varied systematically. 


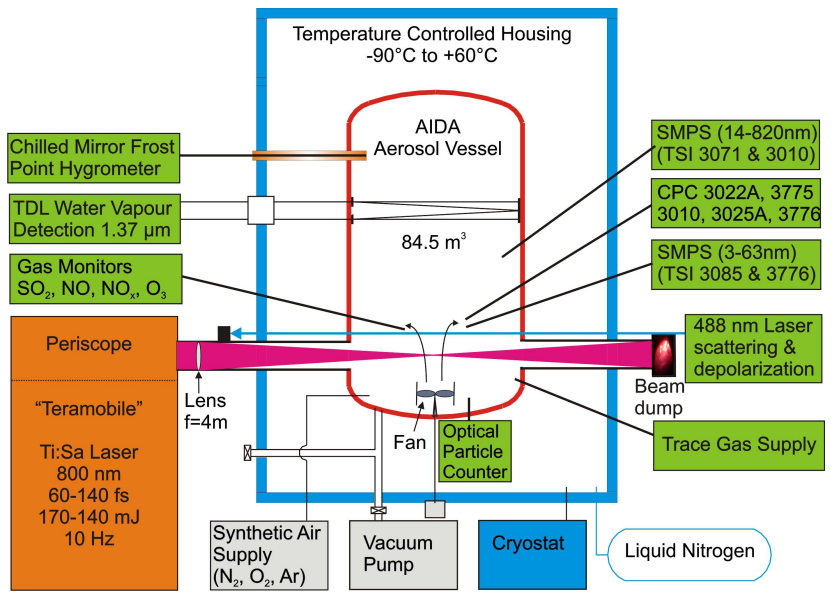

Fig. 1. Schematic of the experimental set-up of the Teramobile laser system at the AIDA aerosol and cloud chamber. The terawatt laser beam (red line) is generated in a container outside the AIDA hall and directed via transfer optics, a focussing lens ( $f=4 \mathrm{~m}$ ), and an entrance window ( $139 \mathrm{~mm}$ diameter, $9.8 \mathrm{~mm}$ thickness) across the AIDA vessel and the air flux from its mixing fan. The beam exits at opposite side through an exit window into a beam dump. Sampling tubes for particles and trace gases are shown as black lines. The light blue line represents the $488 \mathrm{~nm}$ laser beam used for in situ light scattering measurements.

\section{Experimental set-up}

As sketched in Fig. 1, the aerosol and cloud chamber AIDA features $4 \mathrm{~m}$ diameter and $7.5 \mathrm{~m}$ height $\left(84.5 \mathrm{~m}^{3}\right.$ ) (Möhler et al., 2003; Schnaiter et al., 2012). The beam of the Teramobile mobile femtosecond terawatt laser system (Wille et al., 2002) was expanded to $10 \mathrm{~cm}$ diameter and focused by an $\mathrm{f}=4 \mathrm{~m}$ lens into the centre of the AIDA chamber. We used laser pulses at a central wavelength of $800 \mathrm{~nm}$ and a repetition rate of $10 \mathrm{~Hz}$. In two sets of experiments, the pulse energy and duration were $\sim 140 \mathrm{~mJ}, 140 \mathrm{fs}$ ("weak filamentation", generating ten filaments with $100 \mathrm{~cm}$ length each) and $170 \mathrm{~mJ}, 60 \mathrm{fs}$ ("strong filamentation", 20 filaments, $50 \mathrm{~cm}$ length each), respectively. The filaments, of $100 \mu \mathrm{m}$ diameter, covered a volume of typically $80 \mathrm{~mm}^{3}\left(\sim 0.08 \mathrm{~cm}^{3}\right)$ in each case. Shot-toshot laser pulse energy stability was 3\% RMS. Optionally, a mixing fan $\left(31 \mathrm{~m}^{3} \mathrm{~min}^{-1}\right)$ located about $10 \mathrm{~cm}$ below the laser beam homogenized the atmosphere inside the simulation chamber within 1-2 min, diluting the species produced in the filament volume by a factor of about $10^{8}$.

Trace gases were sampled via Teflon tubes (FEP, $4 \mathrm{~mm}$ inner diameter) placed $5 \mathrm{~cm}$ away from the central AIDA axis and the laser beam, directly above the mixing fan. Aerosol particles were sampled through stainless steel tubes located $\sim 15 \mathrm{~cm}$ above the laser beam and $60 \mathrm{~cm}$ away from the central axis of the AIDA chamber, towards the laser exit window. Cloud droplets were sampled via vertical stainless steel tubes in the bottom of the AIDA chamber.
Experiments have been performed within temperature and relative humidity $(\mathrm{RH})$ ranges of $245-283 \mathrm{~K}$ and $25-$ $98 \%$, respectively (cf. Table 1 ). Before each experiment the AIDA chamber was evacuated to about $1 \mathrm{~Pa}$ of total pressure and flushed several times with synthetic air. Then the desired amount of water vapour was evaporated into the evacuated chamber from a stainless steel reservoir containing purified water (Nanopure, Barnstead) at $30^{\circ} \mathrm{C}$, and the chamber was then filled to atmospheric pressure with synthetic air $(99.9990 \%$, hydrocarbons $<0.5$ ppmv, Basi). The atmospheric pressure ranged between 998 and $1016 \mathrm{hPa}$ for the experiments presented in this work. The remaining background particle concentration was $0.1-1 \mathrm{~cm}^{-3}$. Alternatively, argon $(99.9990 \%$, hydrocarbons $<0.1 \mathrm{ppmv}$, Air Liquide), nitrogen $(99.9990 \%$, hydrocarbons $<0.2$ ppmv, Air Liquide), oxygen $(99.998 \%$, hydrocarbons $<0.2$ ppmv, Air Liquide), or ambient air passed through a $\mathrm{PM}_{10}$ inlet (DPM10/2,3/01, Digitel) to remove particles larger than $10 \mu \mathrm{m}$ was used instead of synthetic air. The ambient air filled into the simulation chamber was sampled about $10 \mathrm{~m}$ above ground level on the roof of the AIDA building at KIT campus north near Eggenstein-Leopoldshafen, Germany (latitude: $49.09527^{\circ} \mathrm{N}$, longitude: $8.42938^{\circ} \mathrm{E} ; 112 \mathrm{~m}$ above sea level). Times are given in local time (Central European Summer Time, CEST). Trace gases like $\mathrm{SO}_{2}\left(1 \% \mathrm{SO}_{2}(99.98 \%)\right.$ in nitrogen, Linde) and $\mathrm{NH}_{3}\left(3 \% \mathrm{NH}_{3}(99.995 \%)\right.$ in nitrogen, Linde) were added to the simulation chamber from gas cylinders via a gas handling system with mass flow controllers. Toluene ( $99 \%$, Merck) and $\alpha$-pinene (99\%, Aldrich) were added by evaporation of a well-defined pressure into a $1 \mathrm{~L}$ glass bulb and subsequent flushing into the AIDA chamber with a flow of $10 \mathrm{~L} \mathrm{~min}^{-1}$ synthetic air. Ammonium sulfate aerosol was generated with an atomizer (TSI 3076) from an aqueous solution of $1 \mathrm{wt} \%$ in water and added to the AIDA chamber via a diffusion dryer.

Ozone was measured with $20 \mathrm{~s}$ temporal resolution and a detection limit of $1 \mathrm{ppb}(\mathrm{O} 341 \mathrm{M}$, Environment $\mathrm{SA}) . \mathrm{SO}_{2}$ was measured with $20 \mathrm{~s}$ temporal resolution and a detection limit of $1 \mathrm{ppb}$ (AF22M, Environment SA). NO and $\mathrm{NO}_{\mathrm{x}}$ were measured with $30 \mathrm{~s}$ time resolution and a detection limit of 2 ppb (APNA-300E, Horiba). Water vapour was measured in situ by TDL (tunable diode laser) absorption spectroscopy with $1 \mathrm{~s}$ time resolution and a detection limit of about $100 \mathrm{ppb}$. In addition, the total water concentration was measured outside the chamber with a dew point mirror (373LX, MBW) sampling via a heated stainless steel tube.

The aerosol particle number concentration was measured with five different condensation particle counters (CPC 3010, $3022,3775,3025,3776$, TSI) for particles larger than 10 , $7,4,3$, and $2.5 \mathrm{~nm}$, respectively, with a time resolution of $1 \mathrm{~s}$. If not stated otherwise particle formation rates given in this paper are based on the particle number concentrations measured with the CPC $3025 \mathrm{~A}$ or 3776 for particles larger than 3 or $2.5 \mathrm{~nm}$, respectively. Aerosol particle size distributions were measured with two scanning mobility particle 
Table 1. Experimental conditions for the experiments presented including typical particle production rates observed.

\begin{tabular}{|c|c|c|c|c|c|c|}
\hline No. & $T[\mathrm{~K}]$ & $\mathrm{H}_{2} \mathrm{O}[\% \mathrm{RH}]$ & Main gases & Trace compounds & $\begin{array}{l}\text { Particle production rate* } \\
\qquad\left[\mathrm{cm}^{-3} \text { plasma s }^{-1}\right]\end{array}$ & Fig. \\
\hline 1 & 283.6 & 64 & $100 \% \mathrm{Ar}$ & - & $4 \times 10^{9}$ & 2,3 \\
\hline 2 & 283.6 & 55 & $85 \% \mathrm{Ar}, 15 \% \mathrm{O}_{2}$ & - & $4 \times 10^{8}$ & 2,3 \\
\hline $3 * *$ & 283.1 & 74 & $100 \% \mathrm{~N}_{2}$ & - & $\left(3 \times 10^{9}\right)^{* * *}$ & - \\
\hline 4 & 283.6 & $62(51)$ & $79 \% \mathrm{~N}_{2}, 21 \% \mathrm{O}_{2}$ & - & $3.2 \times 10^{8}\left(1 \times 10^{7}\right)$ & 4,5 \\
\hline 5 & 283.6 & 97 & $79 \% \mathrm{~N}_{2}, 21 \% \mathrm{O}_{2}$ & - & $4.4 \times 10^{9}$ & 6,7 \\
\hline 6 & 283.6 & 60 & $79 \% \mathrm{~N}_{2}, 21 \% \mathrm{O}_{2}$ & $100 \mathrm{vppb} \mathrm{NH}_{3}$ & $3.7 \times 10^{8}$ & 4,5 \\
\hline 7 & 283.6 & 58 & $79 \% \mathrm{~N}_{2}, 21 \% \mathrm{O}_{2}$ & $1 \mu \mathrm{g} \mathrm{m}^{-3}\left(\mathrm{NH}_{4}\right)_{2} \mathrm{SO}_{4}$ & $1 \times 10^{9}$ & 4,5 \\
\hline 8 & 283.6 & 97 & $79 \% \mathrm{~N}_{2}, 21 \% \mathrm{O}_{2}$ & $60 \mathrm{ppb} \mathrm{SO}$ & $2.4 \times 10^{9}$ & 6,7 \\
\hline 9 & 283.1 & 96 & $79 \% \mathrm{~N}_{2}, 21 \% \mathrm{O}_{2}$ & - & $8.0 \times 10^{7}$ & 8 \\
\hline $10 * *$ & 282.8 & 97 & $79 \% \mathrm{~N}_{2}, 21 \% \mathrm{O}_{2}$ & - & $1.4 \times 10^{8}$ & 8 \\
\hline $11 * *$ & 282.7 & 98 & $79 \% \mathrm{~N}_{2}, 21 \% \mathrm{O}_{2}$ & - & $8.0 \times 10^{7}$ & 8 \\
\hline $12 * *$ & 282.7 & 98 & $79 \% \mathrm{~N}_{2}, 21 \% \mathrm{O}_{2}$ & - & $7.1 \times 10^{7}$ & 8 \\
\hline $13 * *$ & 282.9 & 74 & $79 \% \mathrm{~N}_{2}, 21 \% \mathrm{O}_{2}$ & - & $1.5 \times 10^{7}$ & 8 \\
\hline $14^{* *}$ & 283.1 & 50 & $79 \% \mathrm{~N}_{2}, 21 \% \mathrm{O}_{2}$ & - & $1.4 \times 10^{7}$ & 8 \\
\hline $15^{* *}$ & 283.2 & 26 & $79 \% \mathrm{~N}_{2}, 21 \% \mathrm{O}_{2}$ & - & $1.1 \times 10^{7}$ & 8 \\
\hline $16^{* *}$ & 282.6 & 55 & $79 \% \mathrm{~N}_{2}, 21 \% \mathrm{O}_{2}$ & - & $1.0 \times 10^{7}$ & 8 \\
\hline $17 * *$ & 283.1 & 51 & $79 \% \mathrm{~N}_{2}, 21 \% \mathrm{O}_{2}$ & $15 \mathrm{ppb} \mathrm{SO}_{2}$ & $1.8 \times 10^{9}$ & - \\
\hline $18^{* *}$ & 245.1 & 88 & $79 \% \mathrm{~N}_{2}, 21 \% \mathrm{O}_{2}$ & $22 \mathrm{ppb}$ toluene & $1.6 \times 10^{8}$ & - \\
\hline $19 * *$ & 283.0 & 92 & $79 \% \mathrm{~N}_{2}, 21 \% \mathrm{O}_{2}$ & $21 \mathrm{ppb} \alpha$-pinene & $3.6 \times 10^{8}$ & 9,10 \\
\hline $20 * *$ & 283.0 & 90 & $79 \% \mathrm{~N}_{2}, 21 \% \mathrm{O}_{2}$ & $63 \mathrm{ppb} \alpha$-pinene & $1 \times 10^{9}$ & 9,10 \\
\hline $21 * *$ & 283.0 & 89 & $79 \% \mathrm{~N}_{2}, 21 \% \mathrm{O}_{2}$ & 63ppb $\alpha$-pinene, $7 \mathrm{ppb} \mathrm{SO} 2$ & $4.8 \times 10^{9}$ & 9,10 \\
\hline 22 & 283.6 & 76 & Ambient air & & $1 \times 10^{9}$ & 11,12 \\
\hline 23 & 279.3 & 90 & Ambient air & Particles, $15 \mathrm{ppb} \mathrm{NO}_{\mathrm{x}}$ & $1 \times 10^{9}$ & 11,12 \\
\hline
\end{tabular}

* For particles larger than 2.5 or $3 \mathrm{~nm}$. ** Results for weak filamentation. *** Number less precise due to higher particle background in the experiment.

sizers (SMPS, DMA 3071 with CPC 3010 \& DMA 3085 with CPC 3776, TSI) with a time resolution of $300 \mathrm{~s}$ in the size ranges $14-820 \mathrm{~nm}$ and $3-63 \mathrm{~nm}$, respectively. The temperature in both instruments was $296 \mathrm{~K}$ and both used dry sheath air. Particles in the size range $0.5-20 \mu \mathrm{m}$ were measured with an aerodynamic particle sizer (APS 3321, TSI). Size distributions were described by their geometric mean diameter (GMD) and the geometric standard deviation (GSD) of the log-normal size distribution fitted to the measured one. In some experiments aerosol particles from the AIDA chamber were collected on $47 \mathrm{~mm}$ nylon membrane filters (Nylasorb, $1 \mu \mathrm{m}$, Gelman Science) for ion chromatographic analysis (DX500, Dionex) on soluble ions like sulfate and nitrate.

Effective particle formation rates per unit plasma filament volume (hereinafter denoted as $\mathrm{cm}^{-3}$ plasma s${ }^{-1}$ ) were calculated as the increase in measured particle number concentration (particles $>3$ or $2.5 \mathrm{~nm}$ if not stated otherwise) during the laser firing period, divided by the time during which the laser was fired, and by the estimated plasma volume of $0.08 \mathrm{~cm}^{3}$. This effective particle formation aims at quantifying the final result of a specific laser-ionized volume in the cloud chamber. It therefore provides a lower limit to the actual formation rates, since particle losses, e.g. due to self-coagulation or wall losses, directly impact the calculated value. Furthermore, the calculation rates per unit plasma volume do not imply that particles are actually produced within the filament volume itself. They can also be produced in the subsequent evolution of the atmosphere around the filaments, depending on the diffusion of the produced species, as well as their dilution by the mixing fan. While allowing comparisons among the present study, in which all experiments were performed using the same experimental configuration, these limitations should be kept in mind when comparing our data with other experimental arrangements.

We recorded the light scattering by micrometric particles by using a $488 \mathrm{~nm}$ semiconductor laser (Coherent) directed horizontally through the AIDA chamber (Möhler et al., 2003; Schnaiter et al., 2012) in the near-forward direction, at a scattering angle of $2^{\circ}$. Cloud particles (supercooled droplets and/or ice crystals) are counted and sized by two optical particle counters (OPC, WELAS2000, Palas) in the respective size ranges of $0.7-46 \mu \mathrm{m}$ (hereafter denoted OPC1) and $5.0-240 \mu \mathrm{m}$ (OPC2). 


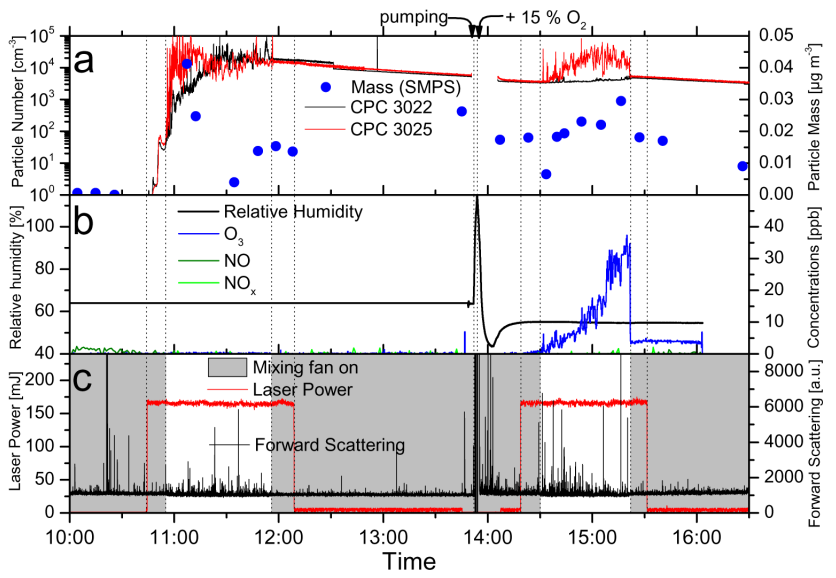

Fig. 2. Particle and trace gas formation by laser filaments for experiments $1 \& 2$ in pure argon and in an argon-oxygen mixture (15\% $\mathrm{O}_{2}$ ) at $283 \mathrm{~K}$ and at $64 \%$ as well as $55 \%$ relative humidity, respectively. The panels show (a) aerosol particle number (black and red lines) and mass concentrations (blue circles); (b) relative humidity (black line), ozone (blue line), $\mathrm{NO}$ (dark green line), and $\mathrm{NO}_{\mathrm{x}}$ concentrations (light green line); (c) as well as near-forward scattering (black line), laser power (red line) and mixing fan operation (shaded grey area). Dashed vertical lines indicate the time of events like switching on/off the laser, the fan, or a pump.

\section{Results and discussion}

In this section we will present and discuss the laser-induced particle formation in atmospheres composed of different main components and trace gases in the order of increasing complexity. We will start with pure humid argon, humid argon-oxygen mixtures, and humid nitrogen and will compare these results with experiments in humid synthetic air. In the following we will demonstrate the potential influence of different trace gases and particles on laser-induced particle formation. These results will then be compared with those obtained in humid ambient air. Finally, we will discuss the cloud activation of the laser-generated particles including growth of the nucleated particles.

\subsection{Plasma-induced particle formation in humid argon, humid argon-oxygen mixtures, and humid nitrogen}

We investigated laser-induced particle formation in an atmosphere consisting only of the noble gas argon and water vapour. In a second experiment $15 \%$ of the argon was replaced by oxygen. We then repeated the experiment also in humid nitrogen.

\subsubsection{Humid argon and humid argon/oxygen atmosphere}

In pure humid argon the laser generated the brightest plasma of all experiments described in this paper. Figure 2 shows the evolution of particle number and mass, relative humid-

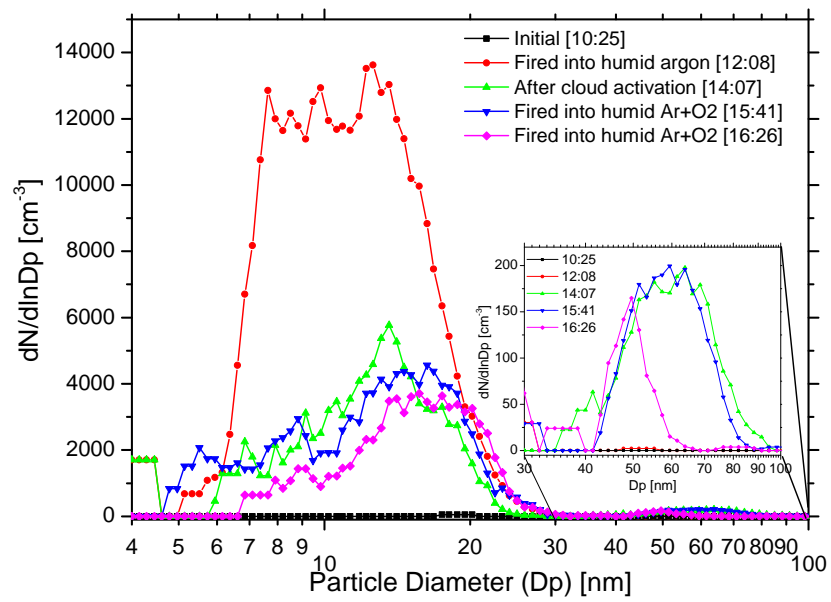

Fig. 3. Particle size distributions for selected times during experiments $1 \& 2$ in pure argon and in an argon-oxygen mixture $(15 \%$ $\mathrm{O}_{2}$ ) at $283 \mathrm{~K}$ and at $64 \%$ as well as $55 \%$ relative humidity, respectively. Times in the legend refer to Fig. 2.

ity and trace gas mixing ratios, forward scattering intensity, laser power and mixing fan operation in three panels. Figure 3 shows particle size (Dp) distributions for different times during the experiment.

The first laser firing period starting at 10:44 CEST and lasting for $85 \mathrm{~min}$ was in humid argon only. The laser generates particles with diameters of 6 to $20 \mathrm{~nm}$ with a concentration of about $2 \times 10^{4} \mathrm{~cm}^{-3}$ in the $84.5 \mathrm{~m}^{3}$ AIDA volume. The particles are produced at an effective rate of $4 \times 10^{9} \mathrm{~cm}^{-3}$ plasma s $\mathrm{s}^{-1}$. This rate is about 10 times higher than in pure synthetic air with similar water content as will be shown in Sect. 3.2. However, the total condensed mass is limited to below $\sim 20 \mathrm{ng} \mathrm{m}^{-3}$, similar as in air (Fig. 2a). The particle mass is calculated from the measured size distributions assuming spherical particles and a density of $1.0 \mathrm{~g} \mathrm{~cm}^{-3}$. Note that the particle production is only visible during the periods when the laser was firing and the mixing fan was not diluting the plasma (cf. Sect. 3.1.2.). The particle number concentration measured by CPC3025 is more sensitive to the smaller freshly formed particles than that measured by CPC 3022 and shows therefore higher concentrations especially when new particles are formed and the mixing fan is off. The forward scattering intensity of the $488 \mathrm{~nm}$ laser near the filaments shows some increased scatter but no significant increase during the formation of the relatively large number of new particles most likely due to their small diameter (Fig. 2c).

At 13:52, $155 \mathrm{hPa}$ of the argon were pumped off and replaced by oxygen. The adiabatic expansion leads to a temporary drop in temperature from 283.6 to $272.4 \mathrm{~K}$ and a corresponding increase in relative humidity from 64 to $115 \%$. This supersaturation activated the existing aerosol particles to cloud droplets. After evaporation of the cloud droplets, aerosol particles of about $60 \mathrm{~nm}$ diameter were observed (see enlarged plot for this size range in Fig. 3). These particles 


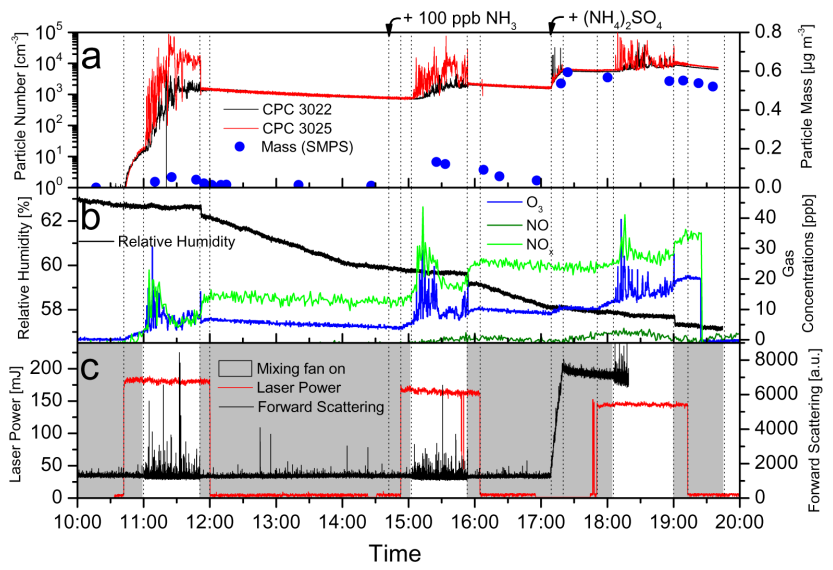

Fig. 4. Particle and trace gas formation by laser filaments in the synthetic air for experiments 4,6 , and 7 at $283 \mathrm{~K}$ and $\sim 60 \% \mathrm{RH}$. The different panels show (a) particle number (red and black lines) and mass (blue circles); (b) relative humidity (black line), ozone (blue line, $\mathrm{NO}$ (dark green line) and $\mathrm{NO}_{\mathrm{x}}$ concentrations (light green line); (c) near-forward scattering (black line), laser power (red line) and mixing fan operation (grey shaded area).

were formed in the dense droplet cloud (e.g. by scavenging processes and not by the laser activity).

At 14:19 the laser started firing for $72 \mathrm{~min}$ into the humid argon-oxygen mixture. The particle number increased only slightly, and no significant increase in particle mass was observed. Only the ozone concentration increased substantially as could be expected from previous measurements (Petit et al., 2010) (Fig. 2b). The particle production is an order of magnitude reduced compared to pure argon. This may partly be due to the decrease of the relative humidity from 64 to $55 \%$ due to the dilution of the moisture by the oxygen injected into the chamber. The reduction in particle production rate by the addition of $15 \%$ of oxygen in the argon atmosphere from $4 \times 10^{9}$ to $4 \times 10^{8} \mathrm{~cm}^{-3}$ plasma s$^{-1}$ is unlikely to stem from a lower plasma density, since the filament clamping intensity (Kasparian et al., 2000; Becker et al., 2001) is similar in both gases. Rather, the electron scavenging effect of $\mathrm{O}_{2}$, or its capacity to generate ozone, may play an important role.

The persistence of new particle formation in argon atmospheres free of elemental nitrogen shows that nitric acid aerosol formation (Henin et al., 2011; Rohwetter et al., 2011) is not the exclusive process that can lead to formation of new particles. As there exist no low vapour pressure species containing just the elements hydrogen, oxygen and argon as present in these experiments, we conclude that the observed particles are related to contaminants in the chamber.

Although the contaminants are not identified and their concentration is unknown, we may roughly evaluate their influence by assuming a contamination of $0.1 \mathrm{ppm}$ of hydrocarbons in the argon, i.e. the upper limit given by Air Liquide. Its complete oxidation in or near the laser-generated plasma

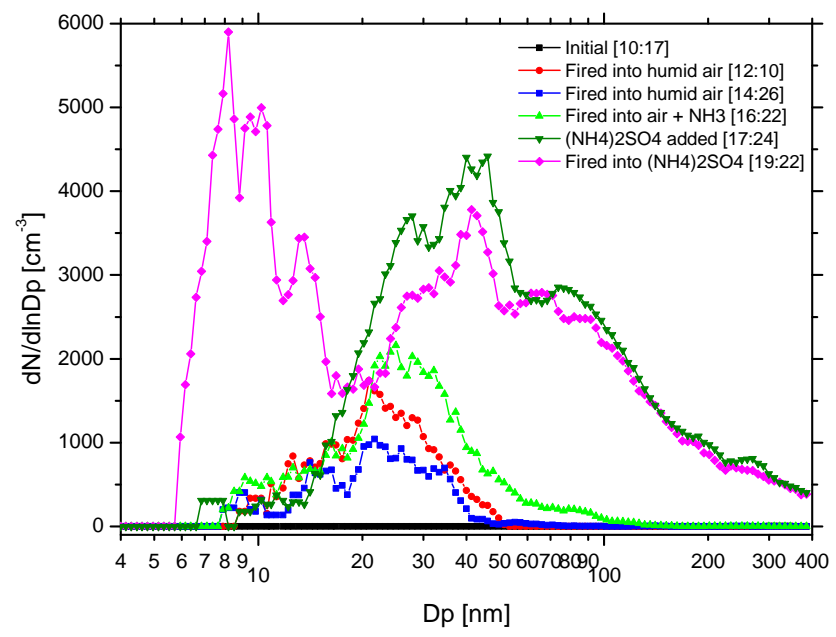

Fig. 5. Particle size distributions for selected times during experiments 4,6 , and 7 in synthetic air at $283 \mathrm{~K}$ and about $60 \%$ relative humidity. Times in the legend refer to Fig. 4.

could potentially lead to formation of about $100 \mu \mathrm{g} \mathrm{m}^{-3}$ of particle mass. This is based on the estimate that $1 \mathrm{ppb}$ of volatile organic hydrocarbon can form $1 \mu \mathrm{g} \mathrm{m}^{-3}$ of particle mass. Considering that every laser pulse $(10 \mathrm{~Hz})$ generates a new plasma volume of $0.08 \mathrm{~cm}^{3}$, about $2880 \mathrm{~cm}^{3}$ of the chamber volume of $84.5 \mathrm{~m}^{3}\left(3.4 \times 10^{-5}\right)$ are processed within one hour. This would correspond to a particle mass formation of a few $\mathrm{ng} \mathrm{m}^{-3} \mathrm{~h}^{-1}$, hence only about a factor of 5 less than the observations. Considering the uncertainties in these estimates and the possibility of additional contamination from the chamber walls, the majority of the particles observed in these experiments may indeed stem from laser-induced oxidation of background volatile organic compound (VOC) in the simulation chamber. The uncertainties about the potential contaminants are of course a limiting factor for the quantitative reproducibility of our experiments, for example, in other experiments.

\subsubsection{Diluting the laser plasma with a fan}

During periods when the mixing fan was switched off, strong local variations (e.g. like moving plumes) of trace gases and particles with high peak concentrations are observed (Figs. 2 and 4). Turning on the mixing fan leads to homogeneous concentrations throughout the whole chamber within about $1 \mathrm{~min}$. Therefore, the amount of trace gases or particles formed by the laser plasma can only be quantified in the periods with the fan operating. Diluting the lasergenerated plasma by using a mixing fan may be compared to atmospheric situations with a similar wind speed of about $1.5 \mathrm{~m} \mathrm{~s}^{-1}$. The dilution does not prevent the formation of active species like ozone and $\mathrm{NO}_{\mathrm{x}}$ (cf. panel b in Figs. 2 (15:25) and 4 (e.g. 10:50)). Their concentrations continue to rise as long as the laser is active no matter if the fan is operating 


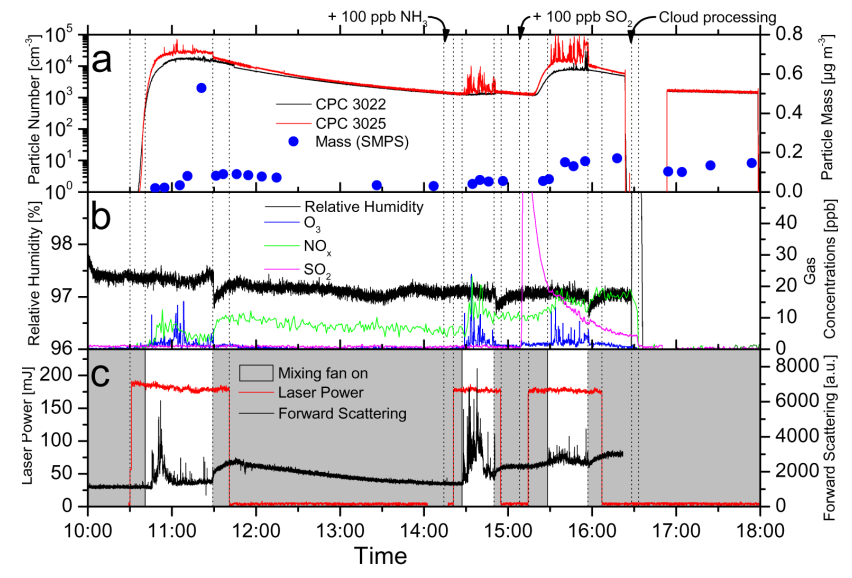

Fig. 6. Particle and trace gas formation by laser filaments in the synthetic air for experiments 5 and 8 at $283 \mathrm{~K}$ and $97 \% \mathrm{RH}$. The panels show (a) particle number (red and black line) and mass (blue circles); (b) relative humidity (black line), ozone (blue line), $\mathrm{NO}_{\mathrm{x}}$ (green line), and $\mathrm{SO}_{2}$ concentrations (magenta line); (c) nearforward scattering (black line), laser power (red line) and mixing fan operation (grey shaded area).

or not. In contrast, new particle formation stops or reduces substantially when the fan dilutes the plasma in both the weak and the strong filamentation regimes. This is visible, for example, in Fig. 9a at 11:55 for weak filamentation and in Figs. 2a and 4a (at 10:50 for both) for strong filamentation. Dilution of the plasma obviously reduces local concentrations of active species (e.g. radicals, atoms, ions), hence reducing reaction rates for formation of condensable molecules available for nucleation of new particles. For these relatively clean conditions in terms of trace gas concentrations, already dilution simulating a moderate wind speed is sufficient to efficiently suppress new particle formation. This is different when additional trace gases are present or for typical ambient air as will be shown in Sects. 3.3 and 3.4.

\subsubsection{Humid nitrogen atmosphere}

In a humid nitrogen atmosphere (74\% RH) in the weak filamentation regime, particle production rates were similar to those in humid argon with strong filamentation. Furthermore, $10-20 \mathrm{ppb}$ of $\mathrm{NO}$ and $\mathrm{NO}_{\mathrm{x}}$ were generated. The particles that were formed by the laser filaments were smaller than $30 \mathrm{~nm}$ in diameter. The relatively high particle production rate despite the weak filamentation may be caused by formation of nitric acid (Henin et al., 2011), a pathway not open in experiments 1 and 2 (Dotan et al., 1997; Bradsley, 1968), as discussed in Sect. 3.1.1. In the humid nitrogen atmosphere, $\mathrm{NO}$ and $\mathrm{NO}_{\mathrm{x}}$ are most probably produced without ozone as intermediate using the oxygen atoms provided by water molecules. This finding illustrates the need to identify other oxidation channels, based e.g. on the $\mathrm{OH}$ radicals, as well as ions and excited species produced in the filament plasma.

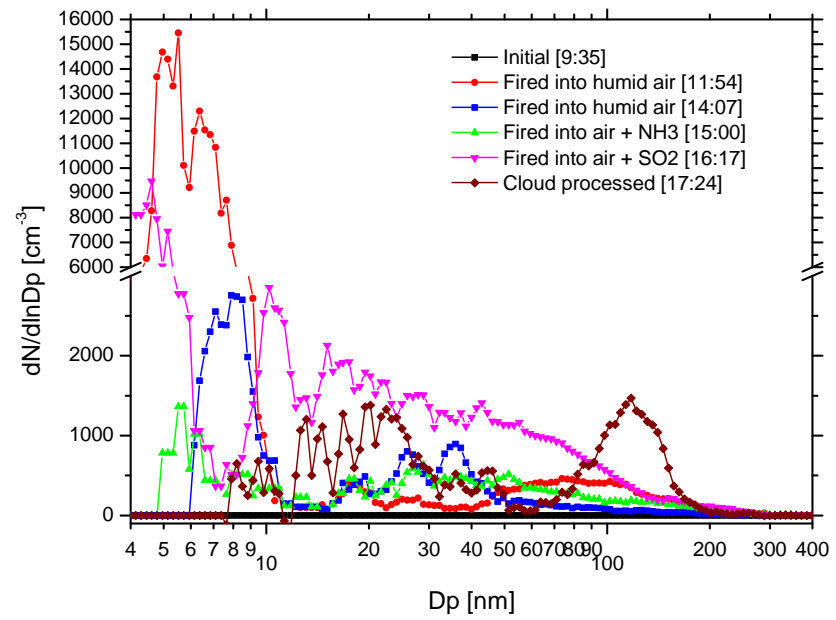

Fig. 7. Particle size distributions for selected times during experiments 5 and 8 in synthetic air at $283 \mathrm{~K}$ and about $97 \%$ relative humidity. Times in the legend refer to Fig. 6.

\subsection{Humid synthetic air atmosphere}

Laser-induced particle and trace gas generation in humid synthetic air will be described in this section as well as the influence of the water concentration.

\subsubsection{Particle and trace gas formation}

Particle and trace gas formation was studied in humid synthetic air for relative humidities ranging from 25 to $99 \%$ at $283 \mathrm{~K}$. Illuminating the chamber atmosphere with laser filaments results in the formation of $\mathrm{NO}_{\mathrm{x}}$, ozone and nanometerscale particles from a low background atmosphere. Two representative experiments are shown for relative humidities of $\sim 60 \%$ (Figs. 4 and 5) and $97 \%$ (Figs. 6 and 7), respectively.

Generating laser plasma for $78 \mathrm{~min}$ in AIDA with the mixing fan switched off for $51 \mathrm{~min}$ led to the formation of $7 \mathrm{ppb}$ of ozone, $13 \mathrm{ppb}$ of $\mathrm{NO}_{\mathrm{x}}$, and $\sim 1200 \mathrm{~cm}^{-3}$ new particles of $18 \mathrm{~nm}$ geometric mean diameter (GMD) and a geometric standard deviation (GSD) of 1.8. These particles were stable at $283 \mathrm{~K}$ and $62 \%$ relative humidity in AIDA, and the integrated mass concentration amounted to about $15 \mathrm{ng} \mathrm{m}^{-3}$. The particle formation rate was $3.2 \times 10^{8} \mathrm{~cm}^{-3}$ plasma s$^{-1}$, about an order of magnitude smaller than those observed in pure argon with $64 \%$ relative humidity. In a similar experiment (laser plasma for $70 \mathrm{~min}$ with $48 \mathrm{~min}$ fan off) at $97 \%$ relative humidity, $2 \mathrm{ppb}$ of ozone, $10 \mathrm{ppb}$ of $\mathrm{NO}_{\mathrm{x}}$, and two separated modes of particles were formed, one with about $16000 \mathrm{~cm}^{-3}$ very small particles ( $\sim 6 \mathrm{~nm}$ GMD, $\left.1.3 \mathrm{GSD}\right)$ and one with about $2000 \mathrm{~cm}^{-3}$ larger particles with a GMD of $101 \mathrm{~nm}$ and a GSD of 1.6. This large concentration of new particles induced a significant increase of the forward scattering signal intensity (cf. Fig. 6c), which was not the case in the experiment at $\sim 60 \%$ relative humidity (cf. Fig. $4 \mathrm{c}$ ). The larger particles formed at $97 \%$ relative humidity seemed 


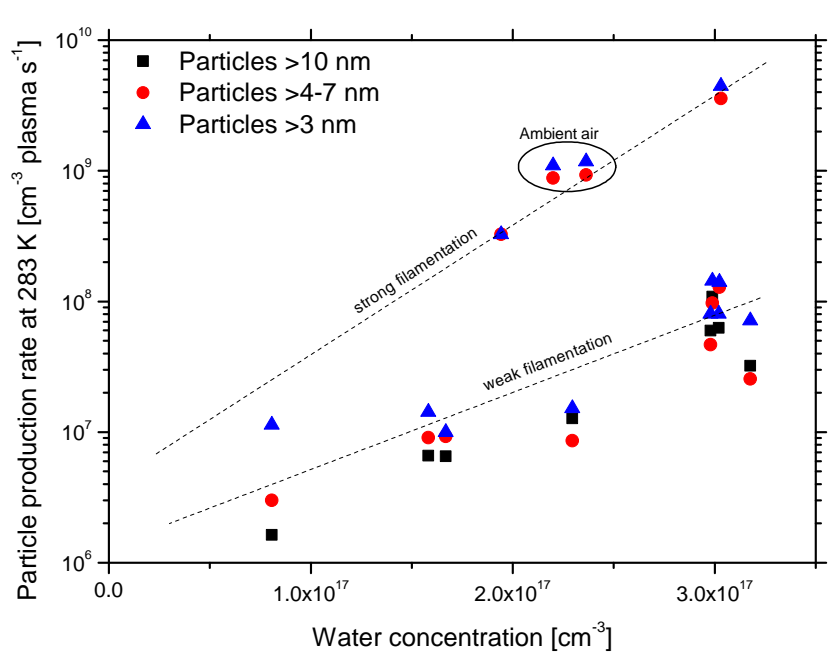

Fig. 8. Formation rates for particles of different sizes in the laser plasma in humid synthetic air at $283 \mathrm{~K}$ for water concentrations between $8 \times 10^{16}$ and $3 \times 10^{17} \mathrm{~cm}^{-3}$. Two experiments with ambient air (cf. Sect. 3.4) are added for comparison. Dashed lines are just to guide the eyes to the results for pure humid air for the two filamentation regimes.

to be less stable than the small ones, which is reflected in a relative fast decrease of the integrated particle mass concentration from initially 90 to $35 \mathrm{ng} \mathrm{m}^{-3}$ over two hours (cf. Fig. 6a). In the experiment with higher humidity, significantly less ozone but similar amounts of $\mathrm{NO}_{\mathrm{x}}$ were formed. The particle formation rate was $4.4 \times 10^{9} \mathrm{~cm}^{-3}$ plasma s$^{-1}$, about an order of magnitude higher than in synthetic air with $62 \% \mathrm{RH}$ but comparable to those observed in pure argon with $64 \%$ relative humidity. The observed differences in particle mass and number are not yet fully understood but may be influenced by the different amounts of water vapour with the higher water concentration favouring the particle formation, e.g. by higher $\mathrm{OH}$ radical yields in the plasma (Fresnet et al., 2002; Gordillo-Vásquez and Donkó, 2009). Furthermore, if the newly formed particles consisted of mainly inorganic molecules like $\mathrm{HNO}_{3}$, their volume would triple and the diameter would double by water uptake when changing the relative humidity from 60 to $97 \%$ (according to the Aerosol Inorganics Model (AIM)(Wexler and Clegg, 2002)). Besides such reasons for the observed differences in the two experiments, the possibility exists that also changing background contaminations of a few ppb of VOCs, which cannot be excluded for these experiments, might have caused them. New nano-size particles were always formed in the AIDA simulation chamber as long as the mixing fan was switched off. In contrast, new particle formation shown in Figs. 4 and 6 is very weak when the laser is turned on and the mixing fan is still working (cf. Sect. 3.1.2). Only when the mixing fan is turned off, the laser-induced particle formation becomes significant.

\subsubsection{Influence of humidity on new particle formation}

The laser plasma-induced particle formation in humid synthetic air is a strong, almost exponential function of the water concentration as shown in Fig. 8 for both filamentation regimes. Note that the scatter in the data stems predominantly from fluctuations in the laser filament intensity, although also variations in the background contamination of the chamber may have an impact. Despite the scatter in the individual data points, the particle formation rate ranges from a few $10^{6} \mathrm{~cm}^{-3}$ plasma s${ }^{-1}$ for weak filamentation up to $5 \times 10^{9} \mathrm{~cm}^{-3}$ plasma s $\mathrm{s}^{-1}$ for strong filamentation for water molecule concentrations between $8 \times 10^{16}$ and $3.2 \times 10^{17} \mathrm{~cm}^{-3}$ corresponding to relative humidities between 25 and $98 \%$ at $283 \mathrm{~K}$. The abundance of water vapour obviously plays an important role for the generation of reactive species, e.g. ions and radicals (Fresnet et al., 2002; Gordillo-Vásquez and Donkó, 2009) in the laser plasma, and therefore can strongly influence the particle formation rates.

Experiments in humid argon and nitrogen show enhanced particle production rates as compared to humid air for similar water concentrations (cf. Table 1). The ambient air experiment, which will be described in Sect. 3.4, seems to be in line with those in synthetic air done also in the strong filamentation regime. Laser power and the corresponding strong or weak filamentation, as well as the water content, control the particle production within the laser plasma. Despite the exponential increase of the particle formation rate with water concentration, the influence of other trace gases can be even higher. Although we have no evidence that our purified water (Barnstead Nanopure) contains significant amounts of impurities, we can not exclude them on a $\sim 50 \mathrm{ppt}$ level, which could potentially impact nucleation. However, experiments with ambient air with no additional water added to the chamber seem to be in line with the water dependence of the particle production observed in humidified synthetic air (Fig. 8). This provides an indication that the interaction of active species (e.g. $\mathrm{OH}$ radicals) generated in the plasma and depending on water concentration, rather than impurities in the nanopure water, promotes particle formation.

\subsection{Influence of trace gases and background particles in humid synthetic air}

\subsection{1 $\mathrm{NH}_{3}$ and ammonium sulfate background aerosol}

$\mathrm{NH}_{3}$ is known to strongly influence particle nucleation (Kirkby et al., 2011), e.g. by stabilizing acidic clusters, and may act as a scavenger of labile photoproducts from the laser plasma. Indeed in the presence of $100 \mathrm{ppb}$ of ammonia (see Fig. $4-15: 00,60 \%$ relative humidity), the increases in particle size (up to $100 \mathrm{~nm}$ ) and mass are larger than in the previous run without ammonia. However, under these conditions, $\mathrm{NH}_{3}$ appears to have no significant influence on the laser-induced particle production rate or the formation of 


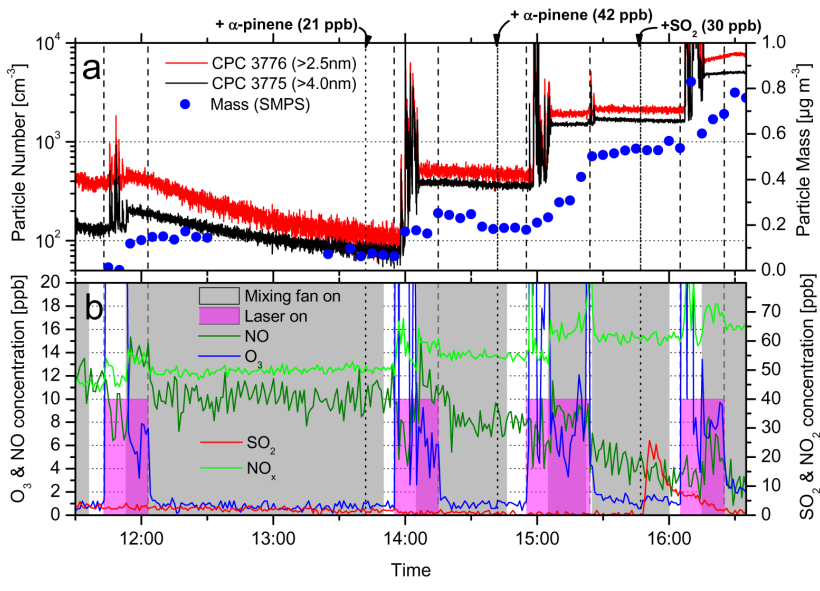

Fig. 9. Laser-induced particle formation in the presence of $\alpha$-pinene and $\mathrm{SO}_{2}$ at $283 \mathrm{~K}$ and a relative humidity decreasing from 94 to $89 \%$, (a) evolution of particle number (red and black line) and mass (blue circles); (b) evolution of $\mathrm{NO}$ (dark green line), $\mathrm{NO}_{\mathrm{x}}$ (light green line), $\mathrm{O}_{3}$ (blue line), $\mathrm{SO}_{2}$ (red line) mixing ratios and operation of fan (grey shaded area) and laser (pink area, $140 \mathrm{~mJ}$ ).

ozone and $\mathrm{NO}_{\mathrm{x}}$. For the experiment at $97 \%$ relative humidity (see Fig. 6 - 14:30, $97 \%$ relative humidity), the addition of $100 \mathrm{ppb} \mathrm{NH}_{3}$ did not increase the particle production rate and had no significant effect on size and mass of the formed particles or the amounts of ozone and $\mathrm{NO}_{\mathrm{x}}$. Probably the effects of the higher water concentration (see Sect. 3.2.2.) mask the potential changes due to the presence of ammonia in this case.

In the experiment presented in Fig. 4 (see 17:10, $60 \%$ relative humidity) $4800 \mathrm{~cm}^{-3}\left(\mathrm{NH}_{4}\right)_{2} \mathrm{SO}_{4}$ aerosol particles with a broad size distribution peaking at $80 \mathrm{~nm}$ were added to the AIDA chamber corresponding to a total mass of $1 \mu \mathrm{g} \mathrm{m}^{-3}$ to represent typical background atmospheric aerosol. With the laser plasma, $4000-5000 \mathrm{~cm}^{-3}$ new particles with a GMD of $10 \mathrm{~nm}$ were produced, which then coagulated predominantly with the larger particles. The new particles may be formed by evaporation of the $\left(\mathrm{NH}_{4}\right)_{2} \mathrm{SO}_{4}$ particles present in the plasma beam and subsequent nucleation of sulfate-containing particles in the diluting plasma. As in the previous experiments, also this new particle formation is suppressed almost completely by enhanced dilution of the filaments with the mixing fan (see Sect. 3.1.2.).

\subsection{2 $\mathrm{SO}_{2}$}

To gain an insight into the mechanism of laser-induced formation of nanometric particles, we also investigated the influence of $\mathrm{SO}_{2}$ (cf. Fig. 6). Firing the laser in a synthetic air atmosphere at $283 \mathrm{~K}$ and $51 \%$ relative humidity with 10 $20 \mathrm{ppb}$ of $\mathrm{SO}_{2}$ resulted in an increase of the particle production rate by two orders of magnitude to $1.8 \times 10^{9} \mathrm{~cm}^{-3}$ plasma s${ }^{-1}$, as compared with the laser effect in an $\mathrm{SO}_{2}$ free atmosphere for weak filamentation. For strong filamentation, the particle formation rates in air and air $+\mathrm{SO}_{2}$ are in

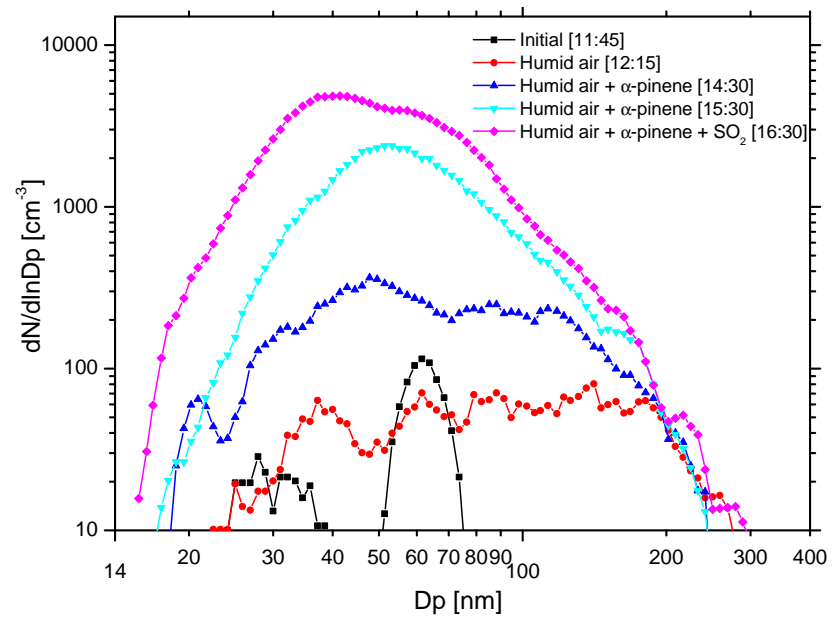

Fig. 10. Evolution of particle sizes for laser-induced particle formation in humid synthetic air in the presence of $\alpha$-pinene and $\mathrm{SO}_{2}$ at $283 \mathrm{~K}$ and $94-89 \%$ relative humidity. Times in the legend correspond to Fig. 9.

the same range of, for example, $2.4 \times 10^{9} \mathrm{~cm}^{-3}$ plasma s $^{-1}$ (cf. Fig. 6, 15:15). The behaviour of the particles formed in $\mathrm{a} \mathrm{SO}_{2}$-doped atmosphere illustrates the difference in the processes leading to particle formation on one side, and their growth on the other side. While in presence of about $10 \mathrm{ppb}$ $\mathrm{SO}_{2}$ the particle production rate increases drastically, the particles stay mostly below $20 \mathrm{~nm}$ and the particle mass increase is not significantly enhanced. In an experiment at $97 \%$ relative humidity, elevated ammonia concentrations, and $\mathrm{SO}_{2}$ decreasing from 60 down to $7 \mathrm{ppb}$ the particle formation started already in the phase when the mixing fan was still in operation (see Fig. 6a). In the presence of $\mathrm{SO}_{2}$, the plasma always generated a large number of particles in the size range below $20 \mathrm{~nm}$, as can be seen exemplarily in Fig. 7 (16:17), where also the number of larger particles increased significantly. The particle volume formed in this experiment after processing of $\mathrm{SO}_{2}$ is consistent with a sulfate mass load of $(0.28 \pm 0.14) \mu \mathrm{g} \mathrm{m}^{-3}$ obtained from filter sample analysis by ion chromatography considering that in Fig. 6a a nominal density of $1.0 \mathrm{~g} \mathrm{~cm}^{-3}$ was used. This is consistent with the measurement of the dry size distribution and would correspond to a conversion of about $70 \mathrm{ppt}$ of $\mathrm{SO}_{2}$ into sulfuric acid in and near the plasma region leading to formation of sulfate particles. The contribution $\mathrm{SO}_{2}$ from beyond the filament volume itself is evidenced by considering that, operating for $52 \mathrm{~min}$ at $10 \mathrm{~Hz}$, the laser filaments process only about $2496 \mathrm{~cm}^{3}$ of the chamber volume of $84.5 \mathrm{~m}^{3}\left(2.95 \times 10^{-5}\right)$. With an average $\mathrm{SO}_{2}$ concentration of $30 \mathrm{ppb}$, this would lead to conversion of only about $0.9 \mathrm{ppt}$ of $\mathrm{SO}_{2}$. Hence, the actual conversion of $\mathrm{SO}_{2}$ into sulfate is about two orders of magnitude more efficient than obtained from this rough estimate. Most of the $\mathrm{SO}_{2}$ must therefore be oxidized by reactive species that are produced in the filament and subsequently 


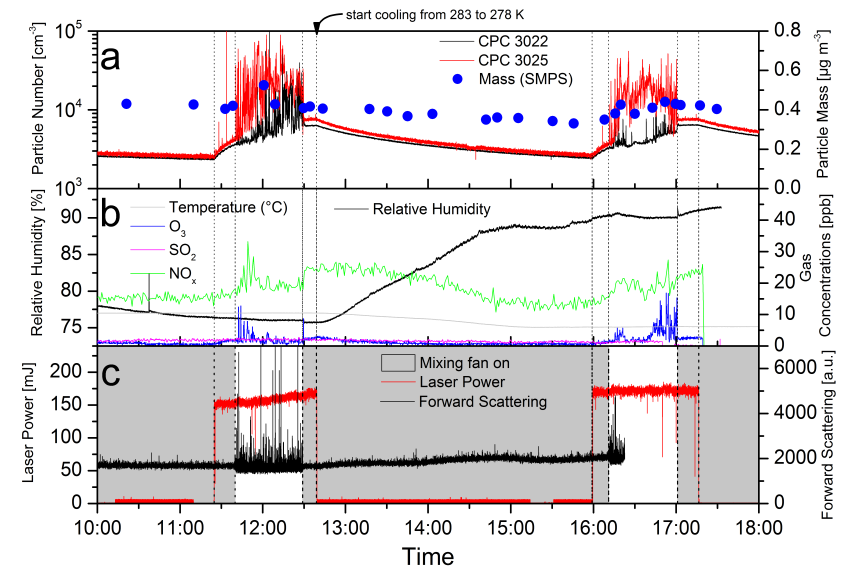

Fig. 11. Particle and trace gas formation by laser filaments in ambient air at $283.6 \mathrm{~K}$ and $\sim 76 \% \mathrm{RH}$ and $279 \mathrm{~K}$ and $\sim 90 \% \mathrm{RH}$. The panels show (a) particle number (red and black line) and mass (blue circles); (b) relative humidity (black line), ozone (blue line), $\mathrm{SO}_{2}$ (pink line), and $\mathrm{NO}_{\mathrm{x}}$ (green line) concentrations; (c) near-forward scattering (black line), laser power (red line) and mixing fan operation (grey shaded area).

dispersed around them by transport and diffusion. A more detailed quantification is however hindered by the limited knowledge about the plasma region and especially the distribution of reactive species like the $\mathrm{OH}$ radicals.

\subsubsection{Toluene and $\alpha$-pinene}

In presence of $22 \mathrm{ppb}$ of toluene at $245 \mathrm{~K}$ and $88 \%$ relative humidity, no significant additional particle mass was formed when the laser fired. Only the particle production rate increased in the weak filamentation regime by a factor of $\sim 6$ from $2.8 \times 10^{7} \mathrm{~cm}^{-3}$ plasma s$^{-1}$ without toluene to $1.6 \times 10^{8} \mathrm{~cm}^{-3}$ plasma s$^{-1}$. This is probably not only caused by negligible reactivity of toluene towards ozone that is formed in the plasma but also by its limited ability to form condensable products in reaction with the active plasma species.

These results are in strong contrast to those obtained for the biogenic hydrocarbon $\alpha$-pinene at $283 \mathrm{~K}$. In presence of $21 \mathrm{ppb}\left(124 \mu \mathrm{g} \mathrm{m}^{-3}\right)$ and $63 \mathrm{ppb}\left(370 \mu \mathrm{g} \mathrm{m}^{-3}\right)$ of the unsaturated terpene $\alpha$-pinene, the particle production rate increases for the weak filamentation regime from $1.4 \times 10^{8} \mathrm{~cm}^{-3}$ plasma s$^{-1}$ before adding the VOC to $3.6 \times 10^{8}$ and $1.0 \times 10^{9} \mathrm{~cm}^{-3}$ plasma s$^{-1}$, respectively (Fig. 9). As observed in absence of VOCs, the increase in particle number is further enhanced by the subsequent injection of $\mathrm{SO}_{2}$ in the chamber. $\alpha$-Pinene does not only assist new particle formation, but also increases the particle size (up to $200 \mathrm{~nm}$ ) resulting from a larger condensable mass. The corresponding particle volume rises up to $0.2 \times 10^{-6} \mathrm{~cm}^{3} \mathrm{~m}^{-3}$ and $0.5 \times 10^{-6}$ (corresponding to 0.2 and $0.5 \mu \mathrm{g} \mathrm{m}^{-3}$ assuming a density of $1.0 \mathrm{~g} \mathrm{~cm}^{-3}$ ), condensing about 0.16 and $0.14 \%$ of the total

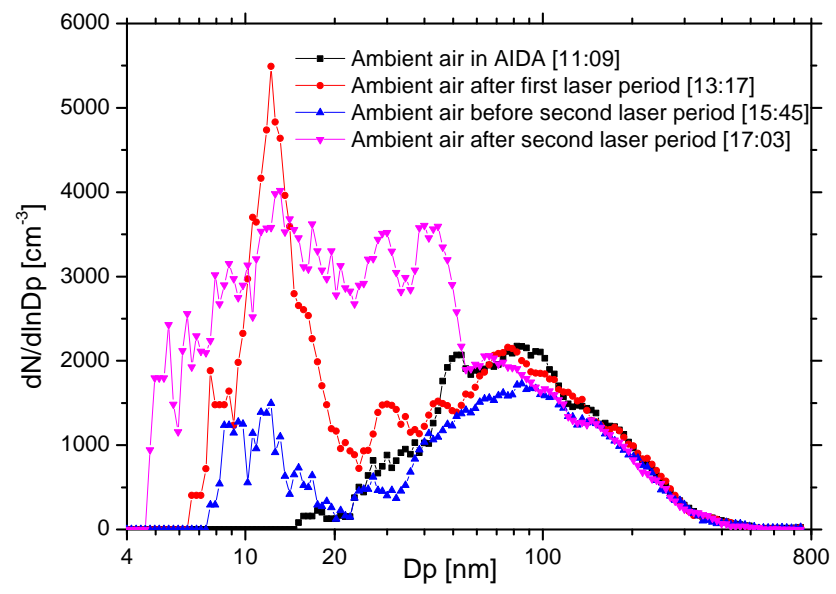

Fig. 12. Particle size distributions for selected times during the experiment with laser filaments in ambient air in the AIDA simulation chamber at $283.6 \mathrm{~K}$ and $\sim 76 \% \mathrm{RH}$ and $279 \mathrm{~K}$ and $\sim 90 \% \mathrm{RH}$. Times in the legend correspond to Fig. 11.

available VOC mass of 124 and $370 \mu \mathrm{gm}^{-3}$, respectively. In case of the unsaturated $\alpha$-pinene, the particle formation proceeds also via its oxidation by the ozone that is formed in the filaments. Therefore, $\alpha$-pinene can promote particle formation also when the laser is not operating, but sufficient amounts of ozone are present. The resulting oxidized species, most probably organic acids, nucleate new particles. This observation evidences the importance of ozone as an intermediate product in the reaction for secondary particle formation. Laser-generated ozone will of course always react with $\alpha$ pinene, which can also lead to new particle formation if the VOC and ozone concentrations are high enough.

In another experiment with synthetic air at $283 \mathrm{~K}$ and $89 \%$ relative humidity, $30 \mathrm{ppb}$ of $\mathrm{SO}_{2}$ were added to the $\alpha$ pinene level of about $63 \mathrm{ppb}$. When the laser fired, $7 \mathrm{ppb}$ of $\mathrm{SO}_{2}$ were still present and the particle production rate was $4.8 \times 10^{9} \mathrm{~cm}^{-3}$ plasma s$^{-1}$, a factor of five higher compared to the gas mixture without $\mathrm{SO}_{2}$. The increase rate in particle mass however did not change significantly. This is also visible in Figs. 9 and 10 by the large number of small particles formed in the presence of $\mathrm{SO}_{2}$.

\subsection{Humid ambient air}

To investigate the effect of the laser-induced plasma in ambient air, we filled the simulation chamber in the morning of 21 October 2011 with ambient air only removing particles larger than $10 \mu \mathrm{m}$ by a $\mathrm{PM}_{10}$ inlet. With the ambient air in the chamber at $283.6 \mathrm{~K}$, a relative humidity of $79-76 \%$ was reached. After the first experiment the chamber was cooled with $3 \mathrm{~K} \mathrm{~h}^{-1}$ to $279 \mathrm{~K}$ increasing the relative humidity to $\sim 90 \%$ for another experiment. The ambient air contained insignificant amounts of ozone $(<2 \mathrm{ppb})$ and $\mathrm{SO}_{2}(<2 \mathrm{ppb})$ but about $15 \mathrm{ppb}$ of $\mathrm{NO}_{\mathrm{x}}$ and $2800 \mathrm{~cm}^{-3}$ particles (Fig. 11) with a size distribution representing the accumulation mode 
size range (20-400 nm) with a GMD of $90 \mathrm{~nm}$ and a GSD of 1.8 as shown in Fig. 12. Analysis of filter samples resulted in a sulfate concentration of $(1.2 \pm 0.6) \mathrm{\mu g} \mathrm{m}^{-3}$, which is more than the mass of $0.7 \mu \mathrm{gm}^{-3}$ calculated from the integrated size distribution using a density of $1.77 \mathrm{~g} \mathrm{~cm}^{-3}$ of $\left(\mathrm{NH}_{4}\right)_{2} \mathrm{SO}_{4}$. This may be explained by a small number of sulfate-containing particles larger than the upper end of the measurement range of the scanning mobility particle sizer of $736 \mathrm{~nm}$.

In contrast to most previous experiments, at $\sim 76 \%$ relative humidity and $283 \mathrm{~K}$, substantial laser-induced particle formation occurred in ambient air even with mixing fan in operation. The particle production rate was $1.1 \times 10^{9} \mathrm{~cm}^{-3}$ plasma s$^{-1}$. The new particles had a peak diameter of $12 \mathrm{~nm}$. Switching off the mixing fan did not significantly change the particle production rate. At $\sim 90 \%$ relative humidity and $279 \mathrm{~K}$, no significant change of the particle production rate compared to the run at $\sim 76 \%$ relative humidity could be observed. However, in contrast to the previous run, the particles formed were larger with diameters of up to $70 \mathrm{~nm}$, and an increase of particle mass by about $0.1 \mu \mathrm{g} \mathrm{m}^{-3}$ could be detected (cf. Fig. 11).

The minimal influence of the mixing fan on particle production can be understood by considering that, contrary to synthetic air where the laser has to produce all reagents implied in the particle formation process, the ambient air contains numerous trace gases already in appreciable concentrations, homogeneously spread in the whole chamber. Therefore, diluting the filament volume is less critical for the formation of condensable species.

\subsection{Cloud processing of laser-generated particles}

In several experiments in the temperature range between 283 and $245 \mathrm{~K}$, the laser plasma-generated particles were activated by adiabatic expansion in the AIDA chamber to form water clouds (Wagner et al., 2006). In all cases most of the particles nucleated water close to water saturation as typical for soluble species. For two different experiments the particle size distributions before and after such cloud processing at $283 \mathrm{~K}$ are shown. Figure 3 (14:07) shows an example for particles generated in pure argon and growing to a mode size of about $60 \mathrm{~nm}$ by single cloud activation. Figure 7 shows this for a sulfate-containing aerosol that forms a particle mode with a size of $120 \mathrm{~nm}$ by cloud processing (see size distribution for 17:24). Since the particle mass concentrations do not increase by cloud processing, the observed increase in particle size may be caused by scavenging of the possibly highly charged aerosol particles by the cloud droplets leading to larger particles once the cloud droplets have lost their water.

Considering the increasing particle formation rates with increasing water concentration or relative humidity, one might wonder if the particle production rates were higher for supersaturated conditions. So far we have not found sig- nificant evidence for this. Furthermore, generating laser filaments in simulated droplet clouds did not seem to significantly change the properties of these clouds. More details of the influence of laser filaments on ice clouds at much lower temperatures will be discussed in a separate paper (Duft et al., 2013).

\section{Conclusions}

Under controlled simulated atmospheric conditions, and especially low background particle concentrations $\left(\leq 0.1 \mathrm{~cm}^{-3}\right)$, terawatt laser plasma filaments generated new particles that grew to sizes of 3 to $130 \mathrm{~nm}$ during the experiment. In weakly polluted ambient air in the simulation chamber, production rates range up to the order of $1 \times 10^{9} \mathrm{~cm}^{-3}$ plasma s$^{-1}$. Although these rates depend on the actual experimental conditions, we may note that it lies 5-6 orders of magnitude above the $10^{4}-10^{5} \mathrm{~cm}^{-3} \mathrm{~s}^{-1}$ observed in coastal areas and industrial plumes (Kulmala et al., 2004), but of course limited to the filament volume.

The new particle formation occurs even in humid inert gas atmospheres in which it is most likely driven by the inevitable presence of lower ppb levels of volatile organic trace contaminants. Adding oxygen to the inert gas reduced the particle production rate by an order of magnitude, which is consistent with the high electron scavenging efficiency of oxygen, reducing the plasma reactivity. In the presence of humid nitrogen, the particle production rates are not significantly enhanced compared to humid argon, although the formation of inorganic species like $\mathrm{HNO}_{3}$ would be possible. In synthetic air, the particle production rate is comparable to that of an argon/oxygen mixture, indicating that nitrogen chemistry (e.g. via $\mathrm{HNO}_{3}$ ) is not the exclusive process for particle production. The new particle formation in synthetic air shows an exponential increase with the water concentration. This points to the important role water molecules play in the formation of clusters (Kurtén et al., 2007) and underlines the relevance of the water molecules for the formation of reactive species like $\mathrm{OH}$ radicals in the plasma, which have the ability to generate condensable species like inorganic acids or oxidized organic molecules (Henin et al., 2011; Fresnet et al., 2002). Without additional trace gases added, the typical particle diameters generated range between 5 and $20 \mathrm{~nm}$. At $97 \%$ relative humidity and $283 \mathrm{~K}$, also surprisingly large particles with a diameter of about $100 \mathrm{~nm}$ could be observed. As expected, the formation and growth of new particles is significantly promoted in the presence of trace gases like $\mathrm{NH}_{3}$, $\mathrm{SO}_{2}$ or volatile organics like toluene or $\alpha$-pinene. While $\mathrm{SO}_{2}$ strongly supports the formation of small particles with limited impact on particle mass, organic species like $\alpha$-pinene have a major impact on particle growth. This different behaviour underlines that several pathways contribute to laserinduced new particle formation and growth: understanding and quantifying the full physico-chemistry of the laser effect 
will require extensive experimental and modelling work well beyond the scope of the present paper.

The particles remained relatively small at $76 \%$ relative humidity and only grew into the accumulation mode size range for a relative humidity of $90 \%$. Under these conditions an increase in particle mass by $30 \%$ was also detectable. Particle production rates were similar to experiments with pure synthetic air at $97 \%$ relative humidity, although it contained initially no particles and trace gases. With ambient air in the simulation chamber, the dilution of the laser plasma had no significant influence on the new particle formation, in contrast to most other experimental conditions reported in this work in which dilution suppressed the laser-induced particle formation. Considering a potential impact of the lasergenerated particles on clouds, we conclude that these particles nucleate water close to water saturation as typical for soluble species.

Acknowledgements. This work was supported by the Deutsche Forschungsgemeinschaft, the Fonds National Suisse de la Recherche Scientifique (FNS, grant \#200021-125315) and EUROCHAMP-2 (Integration of European Simulation Chambers for Investigating Atmospheric Processes), a research project within the EC 7th framework programme (grant E2-2010-04-20-0031). JPW acknowledges financial support from the ERC advanced grant "FilAtmo". The authors are pleased to thank the AIDA team for their support of the measurement campaign.

The service charges for this open access publication have been covered by a Research Centre of the Helmholtz Association.

Edited by: A. Kiendler-Scharr

\section{References}

Bardsley, J. N.: The theory of dissociative recombination, J. Phys. B, 1, 365-380, 1968.

Becker, A., Aközbek, N., Vijayalakshmi, K., Oral, E., Bowden, C. M., and Chin, S. L.: Intensity clamping and re-focusing of intense femtosecond laser pulses in nitrogen molecular gas, Appl. Phys. B, 73, 287-290, 2001.

Béjot, P., Kasparian, J., Henin, S., Loriot, V., Vieillard, T., Hertz, E., Faucher, O., Lavorel, B., and Wolf, J.-P.: Higher-order Kerr terms allow ionization-free filamentation in gases, Phys. Rev. Lett., 104, 103903, doi:10.1103/PhysRevLett.104.103903, 2010.

Bergé, L., Skupin, S., Nuter, R., Kasparian, J., and Wolf, J.-P.: Ultrashort filaments of light in weakly-ionized, optically-transparent media, Rep. Prog. Phys., 70, 1633-1713, doi:10.1088/00344885/70/10/R03, 2007.

Braginskiy, O. V., Vasilieva, A. N., Klopovskiy, K. S., Kovalev, A. S., Lopaev, D. V., Proshina, O. V., Rakhimova, T. V., and Rakhimov, A. T.: Singlet oxygen generation in $\mathrm{O}_{2}$ flow excited by RF discharge: II. Inhomogeneous discharge mode: plasma jet, J. Phys. D: Appl. Phys., 38, 3609-3625, 2005.

Chin, S. L., Hosseini, S. A., Liu, W., Luo, Q., Théberge, F., Aközbek, N., Becker, A., Kandidov, V. P., Kosareva, O. G., and
Schröder, H.: The propagation of powerful femtosecond laser pulses in optical media: physics, applications, and new challenges, Can. J. Phys., 83, 863-905, 2005.

Couairon, A. and Mysyrowicz, A.: Femtosecond filamentation in transparent media, Phys. Rep., 44, 47-189, 2007.

Dotan, I., Hierl, P. M., Morris, R. A., and Viggiano, A. A.: Rate constants for the reactions of $\mathrm{N}^{+}$and $\mathrm{N}_{2}^{+}$with $\mathrm{O}_{2}$ as a function of temperature (300-1800 K), Int. J. Mass Spectrom. Ion Process., 167/168, 223-230, 1997.

Duft, D., Möhler, O., Saathoff, H., Schnaiter, M., Leisner, T., Henin, S., Stelmaszczyk, K., Petrarca, M., Delagrange, R., Hao, Z. Q., Lüder, J., Petit, Y., Rohwetter, P., Kasparian, J., Wolf, J.-P., and Wöste, L.: Laser filament induced ice mulitplication under cirrus cloud conditions, Proc. Natl. Acad. Sci., submitted, 2013.

Fresnet, F., Baravian, G., Magne, L., Pasquiers, S., Postel, C., Puech, V., and Rousseau, A.: Influence of water on NO removal by pulsed discharge in $\mathrm{N}_{2} / \mathrm{H}_{2} \mathrm{O} / \mathrm{NO}$ mixtures, Plasma Sources Sci. Technol., 11, 152-160, 2002.

Gordillo-Vásquez, F. J. and Donkó, Z.: Electron energy distribution functions and transport coefficients relevant for air plasmas in the troposphere: impact of humidity and gas temperature, Plasma Sources Sci. Technol., 18, 034021, doi:10.1088/09630252/18/3/034021, 2009.

Henin, S., Petit, Y., Rohwetter, P., Stelmaszczyk, K., Hao, Z. Q., Nakaema, W. M., Vogel, A., Pohl, T., Schneider, F., Kasparian, J., Weber, K., Wöste, L., and Wolf, J.-P.: Field measurements reveal mechanism of laser-assisted water condensation, Nat. Commun., 2, 456, doi:10.1038/ncomms1462, 2011.

Ju, J., Liu, J., Wang, C., Sun, H., Wang, W., Ge, X., Li, C., Chin, S. L., Li, R., and Xu, Z.: Laser-filamentation-induced condensation and snow formation in a cloud chamber, Opt. Lett., 37, 12141216, 2012.

Kasparian, J. and Wolf, J.-P.: Physics and applications of atmospheric nonlinear optics and filamentation, Opt. Express, 16, 466-493, 2008.

Kasparian, J., Sauerbrey, R., and Chin, S. L.: The critical laser intensity of self-guided light filaments in air, Appl. Phys. B, 71, 877-879, 2000.

Kasparian, J., Rodriguez, M., Méjean, G., Yu, J., Salmon, E., Wille, H., Bourayou, R., Frey, S., André, Y.-B., Mysyrowicz, A., Sauerbrey, R., Wolf, J.-P., and Wöste, L.: White-Light Filaments for Atmospheric Analysis, Science, 301, 61-64, 2003.

Kirkby, J., Curtius, J. Almeida, J., Dunne, E., Duplissy, J., Ehrhart, S., Franchin, A., Gagne, S., Ickes, L., Kurten, A., Kupc, A., Metzger, A., Riccobono, F., Rondo, L., Schobesberger, S., Tsagkogeorgas, G., Wimmer, D., Amorim, A., Bianchi, F., Breitenlechner, M., David, A., Dommen, J., Downard, A., Ehn, M., Flagan, R. C., Haider, S., Hansel, A., Hauser, D., Jud, W., Junninen, H., Kreissl, F., Laaksonen, A., Lehtipalo, K., Lima, J., Lovejoy, E.R., Makhmutov, V., Mathot, S., Mikkila, J., Minginette, P., Mogo, S., Nieminen, T., Onnela, A., Pereira, P., Petaja, T., Schnitzhofer, R., Seinfeld, J. H., Sipila, M., Stozhkov, Y., Stratmann, F., Tome, A., Vanhanen, J., Viisanen, Y., Vrtala, A., Wagner, P.E., Walther, H., Weingartner, E., Wex, H., Winkler, P. M., Carslaw, K. S., Worsnop, D. R., Baltensperger, U., and Kulmala, M.: Role of sulphuric acid, ammonia and galactic cosmic rays in atmospheric aerosol nucleation, Nature, 476, 429-433, 2011.

Kossyi, I. A., Kostinsky, A. Yu., Matveyev, A. A., and Silakov, V. P.: Kinetic scheme of the non-equilibrium discharge in 
nitrogen-oxygen mixtures, Plasma Sources Sci. Technol., 1, 207220, doi:10.1088/0963-0252/1/3/011, 1992.

Kulmala, M., Vehkamaki, H., Petajä, T., Dal Maso, M., Lauri, A., Kerminen, V.-M., Birmili, W., and McMurry, P. H.: Formation and growth rates of ultrafine atmospheric particles: a review of observations, J. Aerosol Sci., 35, 143-176, 2004.

Kurtén, T., Torpo, L., Ding, C.-G., Vehkamäki, H., Sundberg, M. R., Laasonen, K., and Kulmala, M.: A density functional study on water-sulfuric acid-ammonia clusters and implications for atmospheric cluster formation, J. Geophys. Res., 112, D04210, doi:10.1029/2006JD007391, 2007.

Möhler, O., Stetzer, O., Schaefers, S., Linke, C., Schnaiter, M., Tiede, R., Saathoff, H., Krämer, M., Mangold, A., Budz, P., Zink, P., Schreiner, J., Mauersberger, K., Haag, W., Kärcher, B., and Schurath, U.: Experimental investigation of homogeneous freezing of sulphuric acid particles in the aerosol chamber AIDA, Atmos. Chem. Phys., 3, 211-223, doi:10.5194/acp-3-211-2003, 2003.

Petit, Y., Henin, S., Kasparian, J., and Wolf, J.-P.: Production of ozone and nitrogen oxides by laser filamentation, Appl. Phys. Lett., 97, 021108, doi:10.1063/1.3462937, 2010.

Rodriguez, M., Bourayou, R., Méjean, G., Kasparian, J., Yu, J., Salmon, E., Scholz, A., Stecklum, B., Eislöffel, J., Laux, U., Hatzes, A. P., Sauerbrey, R., Wöste, L., and Wolf, J.-P.: Kilometer-range non-linear propagation of femtosecond laser pulses, Phys. Rev. E, 69, 036607, doi:10.1103/PhysRevE.69.036607, 2004.

Rohwetter, P., Kasparian, J., Stelmaszczyk, K., Hao, Z., Henin, S., Lascoux, N., Nakaema, W. M., Petit, Y., Queißer, M., Salamé, R., Salmon, E., Wöste, L., and Wolf, J.-P.: Laserinduced water condensation in air, Nat. Photon., 4, 451-456, doi:10.1038/NPHOTON.2010.115, 2010.

Rohwetter, P., Kasparian, J., Wöste, L., and Wolf, J.-P.: Modelling of $\mathrm{HNO}_{3}$-mediated laser-induced condensation: A parametric study, J. Chem. Phys., 135, 134703, doi:10.1063/1.3644591, 2011.
Schnaiter, M., Büttner, S., Möhler, O., Skrotzki, J., Vragel, M., and Wagner, R.: Influence of particle size and shape on the backscattering linear depolarisation ratio of small ice crystals - cloud chamber measurements in the context of contrail and cirrus microphysics, Atmos. Chem. Phys., 12, 10465-10484, doi:10.5194/acp-12-10465-2012, 2012.

Sorokin, A.: One conceivable mechanism of UV-light induced $\mathrm{SO}_{2}$ Oxidation to $\mathrm{H}_{2} \mathrm{SO}_{4}$, Atmos. Chem. Phys., 10, 3141-3145, doi:10.5194/acp-10-3141-2010, 2010.

Sorokin, A. and Arnold, F.: Analysis of experiments on ion-induced nucleation and aerosol formation in the presence of UV light and ionizing radiation, Atmos. Environ., 43, 3799-3807, 2009.

Wagner, R., Bunz, H., Linke, C., Möhler, O., Naumann, K.-H., Saathoff, H., Schnaiter, M., and Schurath, U.: Chamber Simulations of Cloud Chemistry: The AIDA Chamber. Environmental Simulation Chambers: Application to Atmospheric Chemical Processes, NATO Science Series: IV: Earth Environmental Sciences, 62, 67-82, doi:10.1007/1-4020-4232-9_5, 2006.

Wexler, A. S. and Clegg, S. L: Atmospheric aerosol models for systems including the ions $\mathrm{H}^{+}, \mathrm{NH}_{4}^{+}, \mathrm{Na}^{+}, \mathrm{SO}_{4}^{2-}$, $\mathrm{NO}_{3}^{-}, \mathrm{Cl}^{-}, \mathrm{Br}^{-}$and $\mathrm{H}_{2} \mathrm{O}$, J. Geophys. Res., 107, 4207, doi:10.1029/2001JD000451, 2002.

Wille, H., Rodriguez, M., Kasparian, J., Mondelain, D., Yu, J., Mysyrowicz, A., Sauerbrey, R., Wolf, J.-P., and Wöste, L.: Teramobile: a mobile femtosecond-terawatt laser and detection system, Eur. Phys. J.-Appl. Phys., 20, 183-190, 2002.

Xu, H. L., Azarm, A., Bernhardt, J., Kamali, Y., and Chin, S. L.: The mechanism of nitrogen fluorescence inside a femtosecond laser filament in air, Chem. Phys., 360, 171-175, doi:10.1016/j.chemphys.2009.05.001, 2009.

Yoshihara, K.: Laser-induced Mist and Particle Formation from Ambient Air, A Possible New Cloud Seeding Method, Chem. Lett., 34, 1370-1371, doi:10.1246/cl.2005.1370, 2005. 